\title{
Trade Fairs, Trade Shows, and Exhibitions: A Literature Review: An Abstract
}

\author{
Maria Sarmento and Cláudia Simões
}

\begin{abstract}
Trade fairs, trade shows, or exhibitions are planned events where "manufacturers, distributors and other vendors display their products or describe their services to invited persons including current and prospective customers, suppliers, other business associates and the press" (Bonoma 1983, p.76). Despite the relevance of trade fairs for business, the literature depicts a body of knowledge formed by topical studies conducted from specific backgrounds and contexts. The research focus tends to be fragmented and centered in the individual perspective of each stakeholder with a view to maximize trade fair investments. Yet, recent developments in the literature have enlarged the scope of the field, by bringing comprehensive insights. There has been research in approaching trade fairs from more holistic perspectives, such as relational, learning, and economic geography. Research approaching exhibitor/visitor interaction and business relationships has the underlying idea that trade fairs represent a relevant context for relationship building (e.g., Sarmento et al. 2015). The line of inquiry reporting the trade fair as a context for learning emphasizes the information gathering at trade fairs as part of learning processes for firms (e.g., Bettis-Outland et al. 2012; Tanner et al. 2001). The most overarching inquiry for trade fair studies lies in the dynamic perspective building on economic geography (Power and Jansson 2008), highlighting the trade fair role as collective marketing platforms that industrial agglomerations or geographical clusters can use to sustain their presence internationally (e.g., Rinallo et al. 2016).
\end{abstract}

References Available Upon Request

\author{
M. Sarmento $(\bowtie)$ \\ Nova School of Business and Economics, Lisboa, Portugal \\ e-mail: maria.sarmento@novasbe.pt \\ C. Simões \\ University of Minho, Braga, Portugal \\ e-mail: csimoes@eeg.uminho.pt
}

